9. Diegeler A, Börgermann J, Kappert U, Breuer M, Böning A, Ursulescu A, et al. Off-pump versus onpump coronary-artery bypass grafting in elderly patients. N Engl J Med. 2013;368:1189-98.

10. Tagaki H, Umemoto $\mathrm{T}$. Worse survival after off-pump than on-pump coronary artery bypass grafting. J Thorac Cardiovasc Surg. 2014;148 1820-9.

11. Diegeler A, Hirsch R, Schneider F, Schilling LO, Falk V, Rauch T, et al. Neuromonitoring and neurocognitive outcome in off-pump versus conventional coronary bypass operation. Ann Thorac Surg. 2000;69:1162-6.

12. Zamvar V, Williams D, Hall J, Payne N, Cann C, Young $\mathrm{K}$, et al. Assessment of neurocognitive impairment after off-pump and on-pump techniques for coronary artery bypass graft surgery: prospective randomised controlled trial. BMJ. 2002;325:1268-73.

13. van Dijk D, Spoor M, Hijman R, Nathoe HM, Borst C, Jansen EW, et al. Cognitive and cardiac outcomes 5 years after off-pump versus on-pump coronary artery bypass graft surgery. JAMA 2007;297:701-8.

14. Moller JT, Cluitmans P, Rasmussen LS, Houx P, Rasmussen H, Canet J, et al. Long-term postoperative dysfunction in the elderly: ISPOCD1 study. Lancet. 1988;351:857-61.

15. Selnes OA, Grega MA, Borowicz LM Jr, Barry S, Zeger S, Baumgartner WA, et al. Cognitive outcomes 3 years after coronary artery bypass surgery: a comparison of on-pump coronary artery bypass graft surgery and nonsurgica controls. Ann Thorac Surg. 2005;79:1201-9.

16. Jensen $B \varnothing$, Rasmussen LS, Steinbrüchel DA. Cognitive outcomes in elderly high-risk patients 1 year after off-pump versus on-pump coronary artery bypass grafting. A randomized trial. Eur J Cardiothorac Surg. 2008;34:1016-21.

17. Houlind K. On-pump versus off-pump coronary artery bypass surgery: what is the status after ROOBY, DOORS, CORONARY and GOPCABE? Future Cardiol. 2013;9:569-79.

18. Afilalo J, Rasti M, Ohayon SM, Shimoni A Eisenberg MJ. Off-pump vs. on-pump coronary artery bypass surgery: an updated meta-analysis and meta-regression of randomised trials. Eur Heart J. 2012;33:1257-67.

19. Sabik JF III. On-pump coronary revascularization should be our preferred surgical revascularization strategy. J Thorac Cardiovasc Surg. 2014;148: 2472-4.

http://dx.doi.org/10.1016/

j.jtcvs.2014.12.033

\section{CAN WE DISCUSS BILATERAL INTERNAL THORACIC ARTERY GRAFTS WITHOUT \\ EMBRACING \\ SKELETONIZATION?}

To the Editor:

We read with interest the editorial from our North American colleagues on the issues hampering widespread implementation of multiple arterial grafting in our part of the world. ${ }^{1}$ Whereas our European contemporaries seem to have heard the message, there are still unexplained roadblocks to fulfilling this strategy for our patients.

The editorial emphasizes the disparity between what we should be doing and what is actually being done. All of us seem to recognize that surgeons' concerns regarding mediastinitis play a key role in the decision not to embrace more aggressive use of bilateral internal thoracic artery (BITA) grafts. We do not believe, however, that this dialog can occur in isolation without also discussing the strategy of using skeletonized internal thoracic arteries.

We believe that successful BITA grafting programs are likely to be programs that embrace the technique of skeletonization. Our own studies have shown definitively that skeletonization results in preservation of blood flow in the healing sternum ${ }^{2}$ and that it is associated with a markedly decreased incidence of sternal wound infection, especially in high-risk patients undergoing BITA. ${ }^{3}$ Furthermore, there have been no definitive studies that have challenged long-term outcomes with the use of skeletonized BITA grafts.

We agree that our North American colleagues must get with the times and embrace multiple arterial grafting. Now that we know what to do with regard to how many arterial grafts to use, should we not embrace skeletonization as a means to help us to achieve that goal safely?

Fraser D. Rubens, MD, MSc, FACS, FRCSC $^{a}$

Christopher Feindel, MD, MHA, FRCSC $^{b}$

${ }^{a}$ Ottawa Heart Institute Ottawa, Ontario, Canada ${ }^{b}$ University Health Network Toronto, Ontario, Canada

\section{References}

1. Halkos ME, Guyton RA. Coronary bypass: is it time to take the next step - the routine use of the second arterial graft? J Thorac Cardiovasc Surg. 2014;148:1149-51.
2. Boodhwani M, Lam BK, Nathan HJ, Mesana TG Ruel M, Zeng W, et al. Skeletonized interna thoracic artery harvest reduces pain and dysesthesia and improves sternal perfusion after coronary artery bypass surgery: a randomized double-blind, within-patient comparison. Circulation. 2006;114: 766-73.

3. Peterson MD, Borger MA, Rao V, Peniston CM Feindel CM. Skeletonization of bilateral internal thoracic artery grafts lowers the risk of sternal infection in patients with diabetes. J Thorac Cardiovasc Surg. 2003;126:1314-9.

http://dx.doi.org/10.1016/ j.jtcvs.2014.11.062

\section{FOCUSING ON THE SECOND ARTERIAL CONDUIT}

\section{Reply to the Editor:}

We appreciate the comments of our Canadian colleagues and support the adoption and use of skeletonized bilateral internal mammary artery (BIMA) harvest for multiarterial grafting. Compared with pedicled harvest, skeletonization of internal mammary artery conduits has been shown to preserve sternal blood supply, ${ }^{1,2}$ reduce postoperative chest wall dysesthesia, ${ }^{1,3}$ and most importantly, may reduce the incidence of postoperative sternal complications, ${ }^{4,5}$ especially in higher risk patient cohorts.

However, we believe that our charge to the cardiac surgical community to use an additional arterial graft has a broader reach and effect if we do not impose strict limits or guidelines on how these conduits are harvested. Instead of introducing 2 novel technical challenges to practicing cardiac surgeons (ie, BIMA use and skeletonization), encouraging either the right internal mammary artery for appropriately selected patients or the radial artery for those with appropriate lesions and unfavorable risk profiles for sternal complications has the potential for more widespread adoption among practicing surgeons. Mandating that all patients undergo skeletonization of both internal mammary arteries may discourage surgeons from adopting this approach.

Therefore, we agree that skeletonization may ultimately be the most 
effective method for BIMA harvesting, yet we are reluctant to recommend skeletonization as the sole method for conduit harvest in these patients.

Michael E. Halkos, MD, MSc Robert A. Guyton, MD Division of Cardiothoracic Surgery Joseph B. Whitehead Department of Surgery Emory University School of Medicine Atlanta, $\mathrm{Ga}$

\footnotetext{
References

1. Boodhwani M, Lam BK, Nathan HJ, Mesana TG, Ruel M, Zeng W, et al. Skeletonized internal thoracic artery harvest reduces pain and dysesthesia and improves sternal perfusion after coronary artery bypass surgery: a randomized double-blind, within-patient comparison. Circulation. 2006;114: 766-73.

2. Kamiya H, Akhyari P, Martens A, Karck M, Haverich A, Lichtenberg A. Sternal microcirculation after skeletonized versus pedicled harvesting of the internal thoracic artery: a randomized study. J Thorac Cardiovasc Surg. 2008:135:32-7.

3. Markman PL, Rowland MA, Leong JY, Van Der Merwe J, Storey E, Marasco S, et al. Skeletonized internal thoracic artery harvesting reduces chest wall dysesthesia after coronary bypass surgery. $J$ Thorac Cardiovasc Surg. 2010;139:674-9.

4. Peterson MD, Borger MA, Rao V, Peniston CM, Feindel CM. Skeletonization of bilateral internal thoracic artery grafts lowers the risk of sternal infection in patients with diabetes. J Thorac Cardiovasc Surg. 2003;126:1314-9.

5. Di Mauro M, Iacò AL, Acitelli A, D'Ambrosio G, Filipponi L, Salustri E, et al. Bilateral internal mammary artery for multi-territory myocardial revascularization: long-term follow-up of pedicled versus skeletonized conduits. Eur J Cardiothorac Surg. June 26, 2014 [Epub ahead of print].
}

http://dx.doi.org/10.1016/ j.jtcvs.2014.12.033

\section{RESUSCITATION IN CARDIAC SURGICAL PATIENTS: SYMPTOMS VERSUS CAUSE \\ To the Editor:}

Resuscitation after witnessed cardiac arrest in cardiac surgical patients is a vital issue. The recent Expert Review by Gosev and colleagues ${ }^{1}$ and Editorial Commentary by Pulido $^{2}$ document improved outcomes (up to $79 \%$ survival) relative to nonsurgical setting cardiac arrest resuscitation, for which survival is $23 \%$ and after which approximately $50 \%$ of surviving patients sustain severe neurologic damage. Cardiac surgical advantages are attributed to advanced intensive care unit capabilities, more reversible causes, mechanical circulatory support, or potentially lifesaving emergency resternotomy. Immediate defibrillation before initiating cardiopulmonary resuscitation (CPR) is emphasized, because cardioversion success declines from $78 \%$ after the first shock to $35 \%$ after the second shock and 14\% after the third, with absent response thereafter. Missing is their focus on the basic reasons that cardiac surgical patients have a better response. Sudden cardiac death is the symptom of impaired cardiac action.

Sudden cardiac death after cardiac surgery is a uniquely advantageous event, because we can correct the underlying structural cardiac defect. This differs from noncardiac patients, in whom coronary or valvular disease is frequently present. In contrast, we remedy the defects to improve patient recovery. The bleak area in resuscitation exists when defibrillation is unsuccessful and, despite better hemodynamics after open-chest cardiac massage, negligible survival exists if meaningful spontaneous rhythm is not restored in 10 to 15 minutes. The reasons behind this dilemma relate to the heart sustaining impaired perfusion during CPR, resulting in its lack of recovery. This is somewhat corrected by initiating extracorporeal cardiopulmonary resuscitation, in which circumstance $34 \%$ of patients survive. We must then explain, however, why $66 \%$ of patients die even after the underlying cardiac defect has been corrected. We developed a strategy to answer this question, but it is not considered in these reviews. ${ }^{3}$

The underlying principle involves 3 goals during resuscitation. First, blood pressure should exceed $60 \mathrm{~mm} \mathrm{Hg}$ to improve brain perfusion. CPR at greater than 100 beats/min improves this objective. Second, extracorporeal circulation is needed to improve body perfusion, because negligible flow exists with CPR and is only slightly improved by open-chest cardiac compression. Third, but not needed in our cardiac patients, is going to the catheterization laboratory to find the underlying cardiac cause. Our crucial step is to do resternotomy, insert a vent, clamp the aorta, and deliver a warm substrate-enriched reperfusate for 20 minutes at approximately $50 \mathrm{~mm} \mathrm{Hg}$ perfusion pressure. ${ }^{3,4}$ "Controlled reperfusion" remedies the flow limitations existing in cardiac surgical patients who undergo resuscitation.

This approach was worked out experimentally ${ }^{5}$ and has been shown to be effective in 14 patients in 1989 , as reported in this Journal, ${ }^{4}$ and then in 36 patients in $2006 .^{3}$ The average duration of CPR was 72 minutes, extending to 150 minutes in 1 case. Survival was $79.2 \%$, and brain damage was $6 \%$. It is important that our colleagues are aware of this approach, because it will save the lives of patients who are now considered without hope after failure of the approaches listed in the Expert Review ${ }^{1}$ and Editorial Commentary. ${ }^{2}$

Gerald Buckberg, $M D^{a}$

Constantine Athanasuleas, $M D^{b}$

Friedhelm Beyersdorf, $M D^{c}$

Lance Becker, $M D^{d}$

${ }^{a}$ David Geffen School of Medicine at

$U C L A$

Los Angeles, Calif

${ }^{b}$ University of Alabama at

Birmingham

Birmingham, Ala

${ }^{c}$ Albert-Ludwigs-Universitat-

Freiburg

Freiburg im Breisgau, Germany

${ }^{d}$ University of Pennsylvania

Philadelphia, $\mathrm{Pa}$

\section{References}

1. Gosev I, Nikolic I, Aranki S. Resuscitation practices in cardiac surgery. J Thorac Cardiovasc Surg. 2014;148:1152-6.

2. Pulido JN. Unique aspects of resuscitation practices in postoperative cardiac surgical care: a call to action. J Thorac Cardiovasc Surg. 2014;148:1156-7. 3. Athanasuleas CL, Buckberg GD, Allen BS, Beyersdorf F, Kirsh MM. Sudden cardiac death: 